\title{
Psychiatric and Medical Co-morbidities among the substance abusers presenting at Patna Medical college- A clinical study
}

\author{
Vivek Pratap Singh ${ }^{1}$, Abhishek Pratap Singh ${ }^{2}$, Narendra Pratap Singh ${ }^{3}$ \\ ${ }^{1}$ Senior Resident, ${ }^{3}$ Professor and Head, Department of Psychiatry, Patna Medical College and Hospital, Patna, Bihar \\ ${ }^{2}$ Junior Resident, Department of Medicine, Patna Medical College and Hospital, Patna, Bihar
}

Background: The link between hazardous types of illegal drug use and significant public health issues is a critical issue for national and international drug policy. There are several negative health effects connected with drug use, with the avoidance of both overdose fatalities and drug-related blood-borne diseases being of special importance. However, there has been an increasing understanding in recent decades that the existence of mental illnesses connected with drug use poses a significant barrier for public health interventions. Aims and Objectives: • To investigate the trend of drug misuse in North Bihar Patients. • To determine the co-morbid \& psychiatric medical illnesses. Materials and Methods: It was a cross-sectional research conducted over a one-year period on 200 drug abusers from North Bihar and presenting at Patna Medical College in the Indian state of Bihar. Individuals from the sample were separated into two groups based on their age $(<25$ Years \& $>25$ years) and gender. The pattern of drug abuse, as well as the mental and medical co-morbidities that were linked with it, were investigated in relation to age and gender. Results: The sample size of the present study was 200 consisting of 183 males and 17 females. The total sample was analyzed separately with respect to age and sex. There were 55 patients below 25 years and 128 patients' $\geq 25$ years. The study found that $91.5 \%$ of substance abusers were males. Among the males, $48.6 \%$ were abusing alcohol and $19.1 \%$ were abusing polysubstance. $18.6 \%$ were intravenous drug abusers and $8.2 \%$ showed high risk behavior. Among the females, $29.4 \%$ of the female patients were abusing alcohol. The percentage of women abusing poly-substance was $35.3 \%$ and poly-substance and alcohol was $17.6 \%$. The number of female patients involved in high-risk behavior was only $11.8 \%$. Intravenous drug abuse and high-risk behavior was commoner in age group $<25$ years than in the age group of $>25$ years. $17.5 \%$ received a psychiatric co-morbid diagnosis and $38.5 \%$ received a medical co-morbid diagnosis. The prevalence of schizophrenia and depression among male patients with mental co-morbidity was $63.3 \%(n=19)$, with depression accounting for $6.7 \%(n=2)$. On the other hand, only five female patients, were found to have mental co-morbidity. Conclusion: The large number of young individuals taking intravenous drugs in north Bihar reflects the high level of human-to-human contact with bordering North-Eastern states and Nepal. The situation is critical, and immediate action is required.

Key words: Medical co-morbidities; Psychiatric co-morbidities; Substance Abuse
Access this article online

Website:

http://nepjol.info/index.php/AJMS

DOI: 10.3126/ajms.v12i9.38534

E-ISSN: 2091-0576

P-ISSN: 2467-9100

Copyright (c) 2021 Asian Journal of Medical Sciences

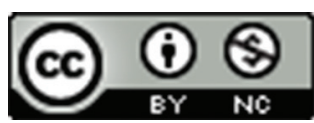

This work is licensed under a Creative Commons Attribution-NonCommercial 4.0 International License.

\section{INTRODUCTION}

Substance abuse, often known as drug abuse, is defined as the use of a substance in quantities or ways that are detrimental to the user or others. It is a kind of substance abuse disorder. Drug abuse is defined differently in public health, medicine, and the criminal justice system. Criminal or anti-social behaviour may occur in some circumstances when a person is under the influence of a drug, and longterm personality changes in individuals may also occur. ${ }^{1}$ 
In addition to potential physical, social, and psychological harm, the use of some substances may result in criminal consequences, which vary greatly depending on the local jurisdiction. ${ }^{2}$

In India, the traditional drugs of usage have been alcohol, opium, and cannabis, with moderate intake being ritualized in social gatherings. ${ }^{3}$ According to studies published in the mid 1970s and 1980s, cannabis, opium, methaqualone, barbiturates, and mild tranquilizers were the most often misused drugs. ${ }^{4,5}$ The first report of heroin usage occurred in $1985 .{ }^{6}$ Since then, drug misuse has been prevalent among high school and college students, as well as non-student adolescents and mental patients. ${ }^{7}$ According to a research on drug abusers performed in 9 metropolitan areas across India, 43 percent were misusing alcohol, 51 percent various opioids, and 6 percent cannabis. ${ }^{8}$ The survey also discovered that the average age of the individuals was 33 years old, that 98 percent were male, that 57 percent were married, and that about 26 percent were jobless. It was also shown that Intravenous Drug Users made up 19\% of all drug abusers, with Manipur having the highest prevalence of IDU $(80 \%)$. A study conducted in 5 different centers in India showed that more than $50 \%$ of the subjects from a particular center have had sex with multiple partners. It also revealed that IDUs shared needles at a rate ranging from $52 \%$ to $81 \%$. The purpose of this study is to assess the drug usage pattern as well as the related medical and mental co-morbidities among outpatients of a tertiary hospital in north Bihar.

\section{MATERIALS AND METHODS}

The current cross-sectional study was conducted in the department of Psychiatric department of Patna Medical College. The study was approved by the Institutional Ethical Committee with Ref No: MF/27(16). The study duration was from January 2019 and December 2019. The sample size was 200 drug abusers' patient who attended the psychiatric OPD during the study period were included matching the inclusion and exclusion criteria.

\section{Inclusion criteria}

- Substance abusers

- Both Sexes.

- Aged $>18$ years.

\section{Exclusion criteria}

- Other psychiatric disorder

- Aged $<18$ Years.

- Patients suffering from any chronic disease (Chronic respiratory disease, Cardiovascular disease, Diabetes, etc).

\section{Study tool}

DSM-5 was used for screening.

\section{Methodology}

A total of 200 substance abusers from North Bihar and presenting at Patna Medical College in the Indian state of Bihar. Individuals from the sample were separated into two groups based on their age and gender. The pattern of drug abuse, as well as the mental and medical co-morbidities that were linked with it.

Substance abusers were defined as those patients who used any or a combination of drugs such as alcohol, heroin, cannabis, cigarettes, benzodiazepines, or other psychoactive substances. Patients who used more than one of the drugs listed above, other than alcohol, at the same time were referred to as polysubstance abusers in this research. The study included all patients who sought consultation between January 2019 and December 2019 regardless of when they sought consultation. The classification of and criteria for psychotic disorders described in the Diagnostic and Statistical Manual of Mental Disorders, Fifth Edition (DSM-5). ${ }^{10}$ When comparing proportions, the Chi square test was utilized. In cases where the frequency of occurrences was lower, the Fischer exact test was employed to compare proportions rather than the Chi-square test. The data was analyzed with the help of SPSS-23.

\section{RESULTS}

The sample size of the present study was 200 consisting of 183 males and 17 females. The total sample was analyzed separately with respect to age and sex. There were 55 patients below 25 years and 128 patient's $\geq 25$ years. The mean age of male patients was $34.215 \pm 11.23$ years (19-68 years). On the other hand, the mean age of female patients was 35.163 years (17-59 years) with SD \pm 12.46 years (Table 1$)$.

According to the gender of the patients, $48.6 \%(\mathrm{n}=89)$ abused alcohol, and $19.1 \%(\mathrm{n}=35)$ abused a combination of drugs. The number of patients who abused polysubstance as well as alcohol was 10 in total (5.5\%). The intravenous method was used by $26.8 \%(\mathrm{n}=49)$ of drug abusers, according to the study. IDUs accounted for $18.6 \%(\mathrm{n}=34)$ of all males in the study. Male patients exhibited high-risk conduct in $8.2 \%(\mathrm{n}=15)$ of their cases (sharing needles, unprotected sex, and multiple sex partners). Female patients, on the other hand, abused alcohol at a rate of $29.4 \%(\mathrm{n}=5)$, according to the data. The percentage of women abusing substance IUDs was $5.9 \%(\mathrm{n}=1)$, while the percentage of women abusing HRB was $11.8 \%(\mathrm{n}=2)$ (Table 2). 
Medical Co-morbidity with respect to sex: was found male patients $37.2 \%$ (68) while female patients $52.9 \%$ (9) respectively (Table 3 ).

Psychiatric Co-morbidity with respect to sex: during the analysis it was found $16.4 \%$ (30) of male patients while $29.4 \%$ (5) female patients respectively (Table 4).

The prevalence of schizophrenia and depression among male patients with mental co-morbidity was $63.3 \%(\mathrm{n}=19)$, with depression accounting for $6.7 \%(\mathrm{n}=2)$. Only five female patients were found to have mental co-morbidity. According to the diagnosis, male and female individuals suffered from bipolar affective disorder (Table 5).

Substance abuse pattern with respect to age: The sample size was divided into two groups, one $<20$ years and the

\begin{tabular}{lccccc} 
Table 1: Age and Sex distribution $(\mathbf{n = 2 0 0})$ \\
\cline { 2 - 6 } Sex & \multicolumn{5}{c}{ Age } \\
& Mean & SD & Maximum & Minimum & Median \\
\hline Male & 34.215 & \pm 11.23 & 68 & 19 & 33.2 \\
Female & 35.163 & \pm 9.865 & 59 & 17 & 35.1 \\
\hline
\end{tabular}

\begin{tabular}{|c|c|c|c|}
\hline $\begin{array}{l}\text { Pattern of } \\
\text { substance } \\
\text { abuse }\end{array}$ & Male(n=183) & Female $=(17)$ & P Value \\
\hline $\begin{array}{l}\text { Alcohol } \\
\text { Alcohol and } \\
\text { Polysubstance } \\
\text { Polysubstance } \\
\text { Intravenous } \\
\text { Drug Users } \\
\text { High risk } \\
\text { behavior }\end{array}$ & $\begin{array}{c}89(48.6 \%) \\
10(5.5 \%) \\
\\
35(19.1 \%) \\
34(18.6 \%) \\
15(8.2 \%)\end{array}$ & $\begin{array}{c}5(29.4 \%) \\
3(17.6 \%) \\
6(35.3 \%) \\
1(5.9 \%) \\
2(11.8 \%)\end{array}$ & $\begin{array}{c}\text { Chi-Square- } \\
8.424 \\
\text { p Value- } 0.077\end{array}$ \\
\hline
\end{tabular}

\begin{tabular}{|c|c|c|c|}
\hline $\begin{array}{l}\text { Medical Co- } \\
\text { morbidities }\end{array}$ & Male $(n=183)$ & Female $=(17)$ & p Value \\
\hline $\begin{array}{l}\text { Present } \\
\text { Absent }\end{array}$ & $\begin{array}{l}68(37.2 \%) \\
115(62.8 \%)\end{array}$ & $\begin{array}{l}9(52.9 \%) \\
8(47.1 \%)\end{array}$ & $\begin{array}{c}\text { Chi-Square- } \\
1.6364 \\
\text { p Value- } 0.200\end{array}$ \\
\hline
\end{tabular}

\begin{tabular}{|c|c|c|c|}
\hline $\begin{array}{l}\text { Psychiatric Co- } \\
\text { morbidities }\end{array}$ & Male $(n=183)$ & Female $=(17)$ & $p$ Value \\
\hline $\begin{array}{l}\text { Present } \\
\text { Absent }\end{array}$ & $\begin{array}{l}30(16.4 \%) \\
153(83.6 \%)\end{array}$ & $\begin{array}{l}5(29.4 \%) \\
12(70.6 \%)\end{array}$ & $\begin{array}{c}\text { Chi-Square- } \\
1.825 \\
\text { p Value- } \\
0.176\end{array}$ \\
\hline
\end{tabular}

other $\geq 20$ years. There were 31 patients $(15.5 \%)<20$ years and 169 patients $(84.5 \%) \geq 20 \mathrm{yrs}$ in substance abusers. $6.4 \%$ of the patients $(\mathrm{n}=6)<20$ years were abusing alcohol while $15.4 \%(\mathrm{n}=2)$ were abusing alcohol and Polysubstance. $34.3 \%(\mathrm{n}=12)$ of the $<20$ years patients had a history of IDU and $35.3 \%(\mathrm{n}=16)$ reported having high risk behavior. In contrast $93.6 \%(\mathrm{n}=88)$ of the patients $\geq 20$ years were abusing alcohol and $87.8 \%(\mathrm{n}=36)$ had a history of polysubstance abuse. Intravenous Drug Users of female cases were $65.7 \%$ (23). $64.7 \%$ (11) female case were reported high risk behavior (Table 6).

\begin{tabular}{|c|c|c|c|}
\hline $\begin{array}{l}\text { Psychiatric Co- } \\
\text { morbidity }\end{array}$ & Male(n=30) & Female $=(05)$ & P Value \\
\hline Schizophrenia & $19(63.3 \%)$ & $02(40 \%)$ & Chi-Square- \\
\hline Depression & $02((6.7 \%)$ & $01((20 \%)$ & 9.333 \\
\hline $\begin{array}{l}\text { Impulse control } \\
\text { disorder }\end{array}$ & $1(3.3 \%)$ & 00 & $p$ Value- 0.500 \\
\hline Sleep & $1(3.3 \%)$ & 00 & \\
\hline Somatization & $1(3.3 \%)$ & 00 & \\
\hline Boderline pd & $1(3.3 \%)$ & 00 & \\
\hline $\begin{array}{l}\text { Generalized } \\
\text { anxiety disorder }\end{array}$ & $1(3.3 \%)$ & 00 & \\
\hline Panic attack & $1(3.3 \%)$ & 00 & \\
\hline Mania & $1(3.3 \%)$ & $02(20 \%)$ & \\
\hline $\begin{array}{l}\text { Restless leg } \\
\text { syndrome }\end{array}$ & $1(3.3 \%)$ & 00 & \\
\hline $\begin{array}{l}\text { Substance } \\
\text { induced } \\
\text { psychiatric } \\
\text { disorder }\end{array}$ & $1(3.3 \%)$ & 00 & \\
\hline
\end{tabular}

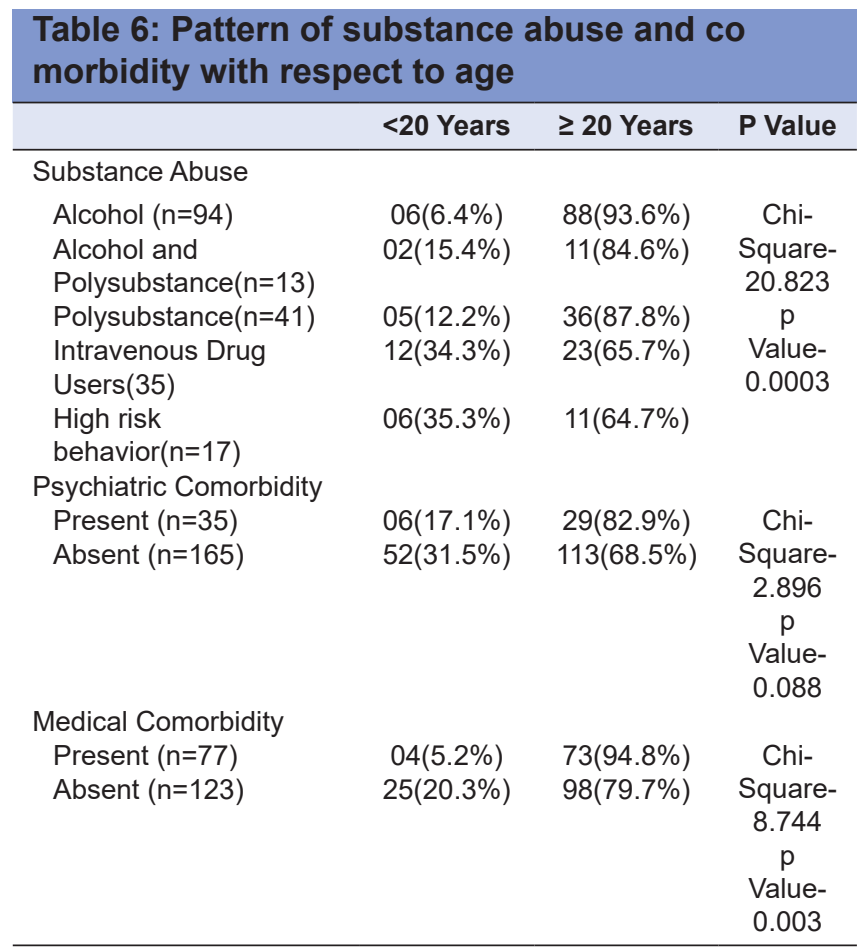

Asian Journal of Medical Sciences | Sep 2021 | Vol 12 | Issue 9 


\section{DISCUSSION}

According to the findings of the current study, $91.5 \%$ (183) of the patients were male, and $48.6 \%$ of the patients were alcoholics. These findings are consistent with the prior findings that alcohol is the most often misused substance and that men are more likely than women to engage in substance abuse (Mittal and Ch'ien 1998). ${ }^{5}$

On the other hands, $29.4 \%$ of the female patients were alcoholics, which was greater than the proportion in previous studies. This can be explained by the fact that women using alcoholic beverages is acceptable in this community and is even considered a component of tribal ceremonies.

The mean age of the patients in the current research is 34 years, which is precisely the same as the age of the patients in the Mittal and Ch'ien study conducted in $1998 .^{8}$

A total of $17.5 \%$ of the abusers in the current research were IDUs, according to the findings. This figure is higher than the national figure of $19 \%$ but lower than the rates of Manipur (80\%). The fact that North Bihar's statistics are higher than the national average might be explained by the state's closeness to Nepal and the north-eastern states.

When Dorabjee and Sampson $(2000)^{10}$ conducted their research, they discovered that $-81 \%$ of "injection" drug abusers were sharing needles with one another However, just $17 \%$ of the respondents engaged in high-risk behavior (which included needle sharing), according to the findings of the current study. This is most likely due to improved patient knowledge of HIV transmission channels and the success of the syringe exchange program, which is administered by nongovernmental organizations (NGOs) and funded by the state government.

Sharma discovered in 1995 that drug addiction is frequent among persons who have been diagnosed with a mental illness. This is mirrored in the findings of the current study, which revealed that $16.4 \%$ of all male patients were given a mental diagnosis in the hospital setting. Females accounted for just $29.4 \%$ of the participants in this study. According to the findings of the current study, $87.8 \%$ of patients under the age of 20 were misusing several substances, with IDUs accounting for $65.7 \%$. This demonstrates the appearance of a shifting trend in drug addiction, as well as an increase in the number of younger individuals at risk.

\section{Limitations of the study}

This study did not include all of the patients who were treated at the tertiary care center. Only those patients who came in for a consultation gave their consent to participate in this study.

\section{CONCLUSION}

As a result of its physical proximity to some of the northeastern states and Nepal, North Bihar has a high incidence of illicit drug users and engages in high-risk behavior. Thousands of people from this region leave Bihar for work and livelihood opportunities in other states in India and Nepal, resulting in greater inter-ethnic contact between the two countries' citizens. In this perspective, the fact that the number of IDUs and the number of young individuals misusing poly-substances is greater than the national average is concerning.

\section{ACKNOWLEDGEMENT}

The authors take this opportunity to thank Department of Psychiatry for their whole hearted support for this study.

\section{REFERENCES}

1. Sadava S W. (1987). Review of Drugs, society, and human behavior (fourth edition) [Review of the book Drugs, society, and human behavior (fourth edition), by O. Ray \& C. Ksir]. Psychology of Addictive Behaviors, 1(2), 125-127. https://doi.org/10.1037/h0084849

2. Peterson J, Sommers I, Baskin D and Johnson D. The Role and Impact of Forensic Evidence in the Criminal Justice Process. NIJ-Sponsored. 2010;11(6): 151. http://dx.doi.org/10.3886/ICPSR29203

3. Ganguly KK, Sharma HK and Krishnamachari KAVR. An ethnographic account of opium consumers of Rajasthan. Addiction. 1995;90: 9-12. https://doi.org/10.1111/j.1360-0443.1995.tb00998.x

4. Murthy P, Manjunatha N, Subodh BN, Chand PK and Benegal V. Substance use and addiction research in India. Indian $\mathrm{J}$ Psychiatry. 2010; 52(Suppl1): S189-S199. https://doi.org/10.4103/0019-5545.69232

5. Jumade PP, Kasbe AM and Giri PA. Socio-demographic profile of male drug abusers residing in Mumbai city, Maharashtra, India. Int J Community Med Public Health. 2016;3(5):1115-1118. https://doi.org/10.18203/2394-6040.ijcmph20161368

6. Mendis N. Heroin addiction among young people: a new development in Sri Lanka. Bull Narc. 1985;37(2-3):25-29. https://doi.org/10.4038/besl.v3i1.7638

7. Sharma B, Arora A, Singh K, Singh $\mathrm{H}$ and Kaur P. Drug abuse: Uncovering the burden in rural Punjab. J Family Med Prim Care. 2017; 6(3): 558-562.

https://doi.org/10.4103/2249-4863.222037 
8. Kumar MS, Mudaliar S, Thyagarajan SP, Kumar S, Selvanayagam $A$ and Daniels D. Rapid assessment and response to injecting drug use in Madras, South India. Int J Drug Policy. 2000; 11(1-2):83-98.

https://doi.org/10.1016/S0955-3959(99)00057-2

9. Dorabjee $\mathrm{J}$ and Samson L. A multi-centre rapid assessment of injecting drug abuse in India. Int J Drug Policy. 2000; 11:99-112. https://doi.org/10.1016/S0955-3959(99)00058-4

10. American Psychiatric Association DSM-5 Task Force. Diagnostic and statistical manual of mental disorders, $5^{\text {th }}$ Edition (DSM-5). Washington, DC: American Psychiatric Association, 2013. https://doi.org/10.1176/appi.books.9780890425596

\section{Author's Contribution:}

VPS-Concept and design of the study; prepared first draft of manuscript; VPS- Interpreted the results; reviewed the literature and manuscript preparation;

NPS- Concept, coordination, review of literature and manuscript preparation; APS- Statistically analysed and interpreted, preparation of manuscript and revision of the manuscript.

\section{Work attributed to:}

Patna Medical College and Hospital, Patna, Bihar. India

Orcid ID:

Dr. Vivek Pratap Singh - (1) https://orcid.org/0000-0002-6780-2484

Dr. Abhishek Pratap Singh- (1) https://orcid.org/0000-0003-1893-0305

Dr. Narendra Pratap Singh- (10 https://orcid.org/0000-0002-6997-5311

Source of Funding: None, Conflict of Interest: None. 